\title{
Gestão de sistemas de produção: uma ferramenta educacional com o método dinâmica de sistemas
}

\author{
RESUMO
}

\section{Igor Tureta Zanchetta} Igortz-10@hotmail.com

Universidade Federal do Norte do Espírito Santo (UFES), Vitória, Espírito Santo
Brasil

\section{Gisele de Lorena Diniz Chaves} Gisele.chaves@ufes.br

Universidade Federal do Norte do Espírito Santo (UFES), Vitória, Espírito Santo Brasil
A compreensão acerca de como a empresa age diante do mercado ou das inúmeras mudanças estratégicas, políticas, organizacionais e mercadológicas que ocorrem com o tempo é estratégica. Apesar da importância, o desafio dos gestores é manter-se atualizado sobre sua organização e as alterações do mercado. Para estudantes, a dificuldade consiste em visualizar o impacto da relação entre estes fatores. 0 método de dinâmica de sistemas é bastante aplicado a tais situações, pois é possível verificar o impacto das variáveis tanto as qualitativas quanto as quantitativas em um sistema complexo. Com isso foi desenvolvido um modelo para gestão de sistemas de produção em que os conceitos de produção enxuta, demanda, atraso, estoque e produtividade são relacionados e diferentes estratégias podem ter seu impacto avaliado. Este modelo utilizou o método dinâmica de sistemas. Ele foi avaliado enquanto ferramenta educacional no ensino do curso de engenharia de produção de uma universidade federal. Verificou-se que a lógica da dinâmica de sistemas aplicada no modelo auxiliou o aprendizado do conteúdo de uma disciplina e possibilitou avaliar os impactos da alteração da estratégia na gestão de sistemas de produção. Os discentes foram receptivos à ferramenta, o que elevou o interesse em outras simulações. Espera-se que este modelo possa ser útil também aos gestores na avaliação do posicionamento da organização em seu ambiente de negócios.

PALAVRAS-CHAVE: Dinâmica de sistema. Gestão e sistema de produção. Ferramenta educacional. Jogos de simulação. Produção enxuta. 


\section{INTRODUÇÃO}

Atualmente, as organizações precisam criar e modificar novas estratégias para se tornarem competitivas no mercado. A busca por novos métodos, novas estratégias e soluções empresariais que ainda não são conhecidas, assume um papel importante para adquirir vantagem competitiva (ROMAN, et al 2012).

A partir da gestão da produção é possível desenvolver novas estratégias organizacionais, com o objetivo de alcançar da melhor maneira possível o seu nicho de mercado. Segundo Pasqualini et al (2010), a gestão da produção é a atividade de gerenciar da melhor maneira os recursos escassos e processos que produzem e entregam bens e serviços, visando atender todas as necessidades dos clientes.

A simulação computacional ou jogos de simulação são ferramentas utilizadas nas empresas para analisar as condições organizacionais ao longo do tempo, auxiliando assim a tomada de decisão para os gestores. Özgün e Barlas (2013) apontam as inúmeras vantagens que jogos de simulação proporcionam, tornando-os ferramentas populares para aprendizagem. Uma das vantagens mencionadas por Özgün e Barlas é a simplificação do sistema complexo providenciando assim uma relação mais direta de feedback para o usuário, cujo aprendizado é mais significativo do que apenas observar o comportamento do mesmo. Leite et al (2014) mencionam os softwares de simulação como uma nova metodologia de ensino para os alunos de engenharia, em que o aprendizado é consolidado de uma maneira diferente quando comparado ao método tradicional de sala de aula. Desta forma é possível aperfeiçoar o conhecimento dos estudantes, formando assim profissionais melhor preparados e, portanto, mais competentes.

Contudo, os softwares de simulação são de difícil acesso financeiro para aquisição, manutenção da licença e treinamentos, limitando sua utilização por empresas de pequeno e médio porte que buscam ferramentas para analisar o comportamento de das variáveis ao longo do tempo e auxiliar os gestores na tomada de decisão. Os softwares de simulação também são limitados para estudantes universitários. Neste caso, o objetivo de utilizar estes softwares é como ferramenta educacional para simular cenários reais encontrados na engenharia, tornando assim o aprendizado mais dinâmico e iterativo.

Jogos de simulação, tal como o beer game (jogo da cerveja), são reconhecidos na engenharia de produção por apresentar o comportamento das variáveis ao longo do tempo em uma cadeia de suprimentos. Daalen et al (2014) mencionam o beer game como um jogo de sequencias lineares, em que os jogadores fornecem os dados para simulação e o comportamento das variáveis ao final da simulação é dependente das tomada de decisões feitas pelos jogadores. O beer game é desenvolvido a partir da metodologia dinâmica de sistemas, em que as variáveis do modelo influenciam todo o sistema. Porém o beer game é um jogo pago com acesso restrito.

A partir da metodologia dinâmica de sistemas, foi elaborado um modelo na área de gestão e sistemas de produção, com o objetivo de desenvolver um sistema que simule os cenários reais encontrados na engenharia de produção. Neste modelo, os conceitos de demanda, produção enxuta, atraso de pedidos e 
estoque são levados em consideração e relacionados de forma a atender o objetivo de minimizar o custo de produção.

O modelo foi construído de forma a ser simulado a partir do software Vensim $\mathrm{PLE}^{\circledR}$, que é a sua versão acadêmica e gratuita, o que garante total acesso aos usuários. Isso torna o modelo desenvolvido uma ferramenta de fácil acesso tanto para os estudantes quanto para profissionais. Com isso, as empresas de pequeno e médio porte que não possuem poder aquisitivo para compra de softwares mais avançados, podem utilizar o modelo como alternativa para tomada de decisão.

Outra vertente do presente trabalho é direcionada para fins didáticos. 0 modelo desenvolvido pode ser utilizado como uma ferramenta educacional para os alunos, com o intuito de complementar o aprendizado por meio de uma visualização do impacto de diferentes estratégias de gestão de produção. Com isso, o modelo também busca incentivar os alunos de engenharia de produção a utilizarem a metodologia dinâmica de sistemas para construção de novos modelos de simulação. Desta forma, espera-se contribuir para a ampliação das possibilidades de simuladores acessíveis utilizados para finalidade acadêmica.

\section{REFERENCIAL TEÓRICO}

A dinâmica de sistemas foi desenvolvida no âmbito do Massachusetts Institute of Technology (MIT) por Jay Wright Forrester como um conjunto de ferramentas e uma abordagem para dar suporte ao controle e à tomada de decisão em indústrias e foi consolidada na obra "Industrial Dynamics", publicada em 1961 (ALVEZ, 2008). Originalmente a metodologia foi utilizada no ambiente industrial, mas depois foram identificadas aplicações em outras áreas de conhecimento, como física, biologia, ciências sociais e ecologia (FORRESTER, 1972). A dinâmica de sistemas é utilizada em diversas áreas de pesquisa, mas também por empresas para auxílio na tomada de decisão (CHUNG et al, 2014).

A dinâmica de sistemas é um método que busca melhorar o aprendizado em sistemas complexos e está relacionada diretamente com o pensamento sistêmico (STERMAN, 2000). Ela analisar o comportamento dos sistemas complexos, incluindo todas as relações de causa e efeito relevantes, os atrasos e os enlaces de retro-alimentação. Uma das ideias do pensamento sistêmico é o feedback, que permite a adaptação dos sistemas ao ambiente por meio da autocorreção a partir do aprendizado (SEDDON; CAULKIN, 2008). Strauss (2010) menciona a dinâmica de sistemas como um entendimento das relações envolvidas no sistema ao longo do tempo utilizando uma linguagem própria para a modelagem, conhecida como simulação computacional.

Vários trabalhos foram desenvolvidos no âmbito da gestão e sistema de produção a partir da dinâmica de sistemas, até porque este campo de estudo foi o que possibilitou o desenvolvimento do método (FORRESTER, 1995). Dentre os vários trabalhos já produzidos, destacam-se alguns na área de programas de manutenção no sistema de produção desenvolvido por Mashayekhi (1996), outros na área de tecnologia e sua influência na competitividade das empresas de manufatura, desenvolvido por Maier (1997) e aplicações da dinâmica de sistemas para a área de reengenharia, desenvolvido por Thurlby e Chang (1994). Orefice e Moraes (2015) mencionam em seu trabalho artigos produzidos a partir 
da dinâmica de sistemas, alguns se destacam nas áreas de estratégia e processos organizacionais, recursos organizacionais, sustentabilidade, recursos naturais e energia, métodos educacionais, economia industrial e transporte. Deif e Elmaraghy (2014) desenvolveram em seu trabalho um modelo que descreve o comportamento de um sistema de célula de manufatura levando em consideração os custos associados à implementação das ferramentas da produção enxuta, tais como just-in-time (JIT), manutenção produtiva total (TPM) e o single minute exchange of die (SMED) e a aleatoriedade da demanda. Os autores mostram em seu artigo o resultado da simulação para o impacto do custo de alocar capacidade escalar no custo total a partir das práticas da produção enxuta, o impacto do limite da capacidade escalar em relação ao custo total do sistema utilizando as políticas enxutas (best lean, average lean e no lean) e por fim os impactos da política de nivelamento de mix de produção em relação ao custo total do sistema.

Trabalhos como Elmasry et al (2012) e Georgiadis e Michaloudis (2012) utilizaram a metodologia dinâmica de sistemas para aplicações na área de manufatura. Elmasry et al (2012) mostram a capacidade que a dinâmica de sistemas possui em modelar condições reais enfrentadas pelos gestores no dimensionamento de capacidade. Além disso, seu estudo avalia o impacto da capacidade sazonal em sistemas escalares.

Georgiadis e Michaloudis (2012) desenvolvem um modelo de PCP (Planejamento e Controle da Produção) em tempo real para indústrias que utilizam o método job-shop (pedido sob encomenda). O modelo proposto pelos autores prevê possibilidades para tomadas de decisões em tempo real sobre fluxo de materiais, monitoramento contínuo do sistema, capacidade de integrar a aleatoriedade do sistema e adaptação dinâmica dos estados do sistema. A simulação realizada pelos autores teve como objetivo identificar os parâmetros ótimos para o PPC. Porém, ao comparar com o cenário real, não foi possível utilizar os valores ótimos para alguns parâmetros devido às limitações encontradas no ambiente externo. Com isso, foi identificada a melhor combinação para os parâmetros do sistema, cujo objetivo é de minimizar os custos. Embora o modelo de Georgiadis e Michaloudis (2012) foi desenvolvido para um cenário específico de job-shop, o sistema pode ser adaptado para outros cenários.

Haag e Tilebein (2012) desenvolveram um modelo para analisar as estratégias organizacionais de uma rede de produção a partir da dinâmica de sistemas. O modelo desenvolvido pelos autores busca identificar o impacto de variáveis chave do sistema para auxiliar a tomada de decisão em longo prazo. As principais variáveis que compõe o sistema são: demanda, lucro, preço de mercado, custos e nível de atratividade do produto ao consumidor final e as variáveis chaves são encontradas no modelo como restrições de vendas e produtos concorrentes. A simulação foi realizada a partir de três cenários, em que o primeiro consiste no cenário futuro positivo, o segundo com o cenário atual e o terceiro representa o cenário futuro negativo. Após a simulação foi desenvolvido um modelo genérico do modelo para que seja aplicado em outros casos.

Outro tema bastante estudado na gestão da produção é a produção enxuta, Drews et al (2016) apresentam um modelo para auxiliar a tomada de decisão levando em consideração o princípio da produção enxuta. Os autores utilizam 
dois princípios da produção enxuta, o SMED (single minute exchange of die) e o KAIZEN para avaliar o comportamento dinâmico do sistema. Os resultados mostram que ao adotar o SMED, o tempo de setup, tempo de processamento e estoque de produto semiacabado são reduzidos. Ao aplicar o KAIZEN, a simulação demonstrou resultados positivos, com uma redução no tempo de produção e funcionários requeridos para a atividade enquanto houve um aumento na produtividade.

O modelo desenvolvido neste artigo foi baseado no trabalho de Deif e Elmaraghy (2014). Os autores utilizaram a dinâmica de sistemas para identificar o comportamento do custo total de um sistema ao longo do tempo, utilizando as práticas da produção enxuta. O modelo foi adaptado e modelado para ser mais didático e prático para as simulações, conforme a Figura 1. As diferentes cores das variáveis servem para destacar aquelas que foram alteradas para a simulação, o que será detalhado na etapa 1 do procedimento de pesquisa (próxima seção).

Figura 1: Modelo de gestão e sistemas de produção

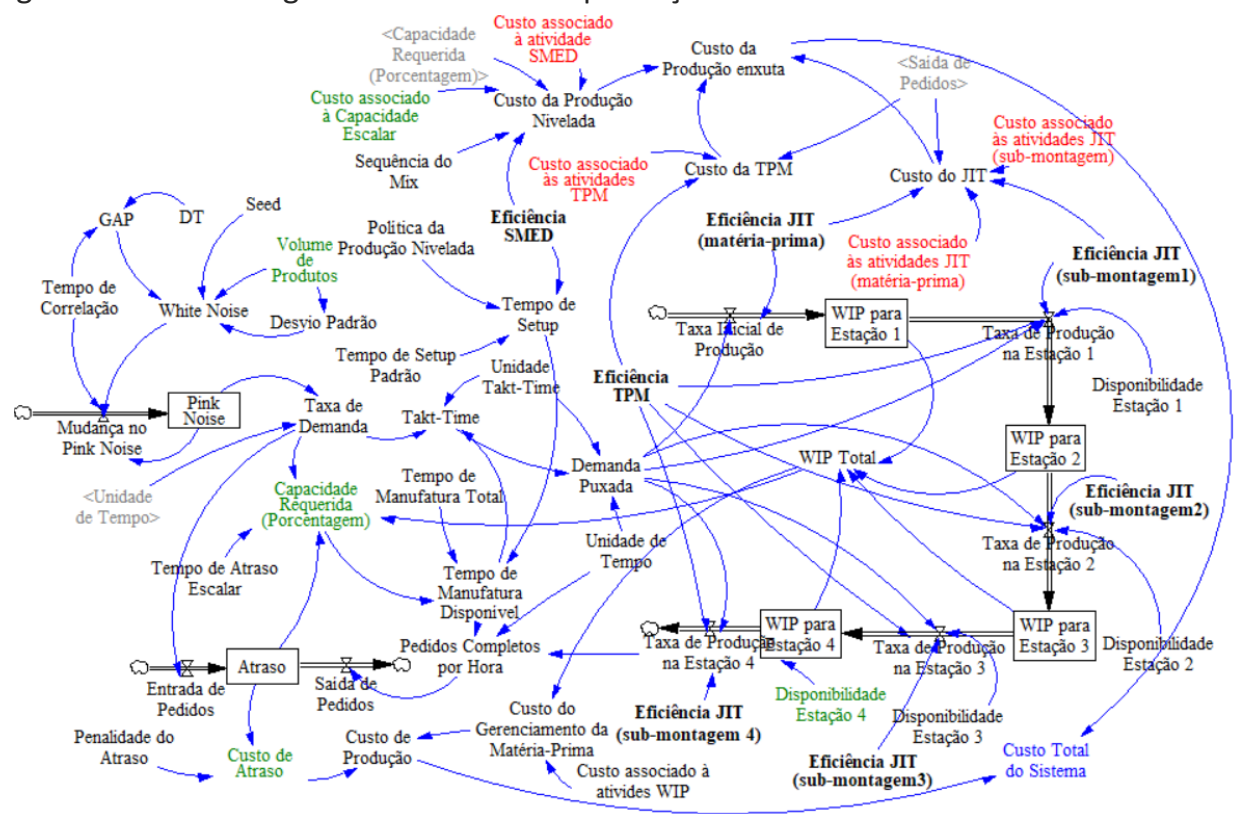

Fonte: Adaptado de Deif e Elmaraghy (2014)

O modelo da Figura 1 representa um sistema de manufatura, cuja produção consiste em um mix de produtos com três estágios produtivos. O sistema é influenciado por uma demanda variada, que é determinado pelo Pink Noise e White Noise. Para o cálculo da demanda é inserido um volume de produtos inicial (média de pedidos dos clientes) e seu desvio padrão (20\% do volume de pedidos), em seguida é utilizado o Pink Noise e White Noise para simular o comportamento oscilatório da demanda ao longo do tempo dentro de uma faixa, tornando assim o modelo dinâmico e próximo ao real.

Sterman (2000) define o White Noise como uma variação aleatória gerada pelo sistema que, estatisticamente, descreve o comportamento do sistema de mudanças rápidas em um curto período. Porém, o White Noise não se aplica aos cenários reais de engenharia, pois os estes possuem uma inércia, ou seja, as mudanças são feitas gradualmente, diferentemente das rápidas mudanças do 
White Noise. Para modelar um sistema real é necessário utilizar o Pink Noise, em que a inércia é levada em consideração. O Pink Noise é formulado a partir do White Noise, mas que incorpora algum tipo de atraso de informação para suaviza-lo. Os atrasos de informações representam as fontes de inércia dos sistemas reais. Sendo assim, o Pink Noise tem a função de filtrar as informações úteis para o sistema com o objetivo de tornar o sistema o mais próximo da realidade (STERMAN, 2000).

A demanda influencia diretamente outras três variáveis do sistema, o TaktTime, entrada de pedidos e a capacidade requerida do sistema. Segundo Antunes et al (2008), o Takt-Time é definido como o ritmo da produção em um determinado período, cujo objetivo é atender as necessidades de demanda do mercado. A partir do Takt-Time é calculada a taxa inicial de produção e a taxa de produção nas estações 1,2 e 3 . Com a taxa de produtos acabados, é possível calcular o atraso do sistema, em que a saída de pedidos representa a quantidade de pedidos completo por hora e a entrada de pedidos consiste na taxa de demanda calculada.

O modelo possui característica de uma produção nivelada, ou seja, sua capacidade é alterada para nivelar o mix de produção de acordo com a necessidade. Para incorporar este comportamento, o tempo de manufatura disponível é calculado a partir da capacidade requerida do sistema, tempo de setup e tempo de manufatura total (representa o tempo de operação da indústria: $8 \mathrm{~h} / \mathrm{dia}, 40 \mathrm{~h} / \mathrm{semana})$. 0 tempo de setup pode ser definido como o tempo entre a troca de um mix de produto para outro, ou seja, o tempo total para alteração do mix de produção (FERRADÁS; SALONITIS, 2013). Sendo assim, o tempo de setup no modelo proposto é calculado a partir da política da produção nivelada (quantidade de família de produtos), tempo de setup padrão (tempo de setup para cada família de produto) e a eficiência SMED. A eficiência SMED é utilizada no modelo como porcentagem de redução de setup, e está relacionada à ferramenta da produção enxuta Single Minute Exchange of Die (SMED).

A capacidade requerida do sistema é utilizada na forma de porcentagem e representa o quanto de capacidade adicional o sistema precisa para atender uma determinada variação na demanda. Para o calculo da capacidade requerida é necessário a taxa de demanda, atraso de pedidos, o WIP total (total de produtos em processamento) e o tempo de atraso escalar. O tempo de atraso escalar consiste no tempo necessário para alocar a capacidade, e o sistema é escalar porque ao alocar capacidade adicional (mão-de-obra, turno extra, equipamento) o sistema altera seu nível de capacidade instantaneamente, porém há um tempo para que isso ocorra. Em relação aos produtos em processamento, que são os estoques em processamento do sistema, é determinado pelo somatório dos estoques nas três estações produtivas. Os estoques nas estações 1, 2 e 3 são determinados pela diferença da taxa de produção da estação atual pela taxa de produção da estação anterior.

A taxa de produção do sistema é influenciada pelo Just-in-Time (JIT) e a manutenção produtiva total (TPM), enquanto a ferramenta SMED auxilia no nivelamento do mix de produção. O sistema Just-in-Time (JIT) é uma filosofia japonesa cujo objetivo fundamental é a melhoria contínua do processo produtivo por meio de um mecanismo de redução de estoque, eliminação de desperdício e produzir somente quando necessário (WOMACK; JONES, 1996; SAVSAR; ABDULMALEK, 2008). A manutenção produtiva total (TPM) é uma metodologia 
que visa aumentar a disponibilidade de equipamentos existentes, reduzindo assim a necessidade de mais investimentos de capital (AHMAD et al, 2012).

As ferramentas da produção enxuta são utilizadas no modelo como eficiências. A eficiência JIT para matéria prima e para sub-montagem representam o nível de confiabilidade que as unidades chegam à estação de produção. Já a eficiência TPM consiste na porcentagem adicional da disponibilidade do equipamento justificada pela implementação desta ferramenta.

Para a implementação das ferramentas da produção enxuta no modelo, é necessário um investimento inicial. Com isso, o custo da produção enxuta é calculado a partir da soma do custo da produção nivelada, custo da TPM e custo do JIT. O custo da produção nivelada consiste no custo para manter no nível de produção ideal, em que é influenciada diretamente pela capacidade requerida do sistema. O custo da TPM representa o custo de implementação da ferramenta, sendo influenciada pela quantidade de volume de produtos que sai da estação de produção e seus respectivos custos de atividade, assim como o custo do JIT que é determinado pelo custo associado às suas atividades de implementação e a saída de pedidos do sistema.

O custo total do sistema é calculado a partir da soma do custo de produção com o custo da produção enxuta. $O$ custo de produção é determinado a partir da soma do custo de gerenciamento da matéria-prima com o custo de atraso. 0 custo de gerenciamento da matéria-prima representa o custo necessário para manter os estoques de produtos acabados e em processamento do sistema produtivo enquanto o custo de atraso é determinado a partir do acúmulo de pedidos com uma penalidade, ou seja, o quanto é custoso para a empresa perder seus clientes devido a atrasos de pedidos.

\section{PROCEDIMENTOS DE PESQUISA}

Esta pesquisa foi realizada em duas etapas, a primeira etapa consistiu em equacionar o modelo da Figura 1 e simular o sistema a partir de parâmetros prédefinidos. Com isso, foi identificado o comportamento das variáveis chave do modelo ao longo do tempo em função do custo total do sistema. A segunda etapa consistiu em apresentar o modelo desenvolvido para estudantes do curso de engenharia de produção, com o objetivo de avaliar o impacto da simulação como ferramenta educacional.

\section{PROCEDIMENTOS DA ETAPA 1}

Primeiramente para a elaboração do modelo, foi determinada a delimitação do sistema e o objetivo do modelo a ser construído. Nesta etapa, por meio da revisão bibliográfica, buscou-se identificar aplicações reais que abordam a gestão de sistema de produção utilizando a dinâmica de sistemas e definir o cenário específico que representará o sistema. Este trabalho se baseou no modelo de Deif e ElMaraghy (2014). O método utilizado para simulação foi a computacional, por meio do software livre Vensim $\mathrm{PLE}^{\circledR}$. O modelo estruturado, equacionado e validado, seguiu então para a análise de resultados. A partir da dinâmica de 
sistemas foi possível verificar o impacto dos resultados obtidos a partir da simulação realizada no software.

Para as simulações, três políticas da produção enxuta (best lean, average lean, no lean) foram utilizadas para comparar os resultados, com o objetivo de identificar a melhor política para determinado cenário. A primeira política da produção enxuta consiste na best lean, em que a eficiência do sistema é a máxima possível, porém seu custo de investimento é alto quando comparado às demais políticas. A average lean representa as práticas da produção enxuta em nível intermediário, ou seja, sua eficiência é inferior à best lean e superior à no lean, enquanto seu custo de investimento é superior à no lean e inferior à best lean. Por fim a no lean consiste na política sem a implementação das ferramentas da produção enxuta, o que torna seu custo de investimento mínimo possível, porém a eficiência do sistema é inferior quando comparado às demais políticas. As variáveis do modelo que devem ser alteradas para estas três políticas foram destacadas em vermelho na Figura 1.

As simulações foram realizadas a partir de três propostas estabelecidas para verificar se o modelo elaborado condiz com os cenários reais encontrados na engenharia. Na Figura 1, as variáveis do modelo que devem ser alteradas para estes três cenários foram destacadas em verde. A primeira proposta consistiu em avaliar o impacto do custo total do sistema utilizando as políticas enxutas (best lean, average lean e no lean) quando há alteração no custo de alocar capacidade, para isso três cenários distintos foram propostos, sendo eles: (1) custo de alocar capacidade escalar igual a $10 \$,(2)$ custo de alocar capacidade igual a $\$ 5$ e (3) custo de alocar capacidade igual a \$1.

A segunda proposta consistiu em avaliar o impacto do custo total utilizando as políticas enxutas (best lean, average lean e no lean) quando o sistema é limitado pela sua capacidade, ou seja, a capacidade requerida para atender a demanda terá um limite máximo. Três cenários diferentes foram criados, sendo eles: (1) capacidade máxima igual a 50\%, (2) capacidade máxima igual a $25 \%$ e (3) capacidade máxima igual a $12,5 \%$.

Por fim, a terceira proposta consistiu em avaliar o impacto do custo total do sistema a partir de uma penalização por atraso causada pelo sequenciamento da produção. Utilizando somente a política best lean a comparação do custo total foi realizada a partir de dois tipos de sequenciamento, o primeiro consiste em uma produção de lotes maiores e quatro setups ao mês e uma semana de atraso, ou seja, um sequenciamento de mix do tipo $A B A B$. O segundo consiste em uma produção de lotes menores e dois setups ao mês com duas semanas de atraso, ou seja, um sequenciamento de mix do tipo AABB.

Os parâmetros utilizados na simulação podem ser obtidos no sítio eletrônico https://igortz-10.wixsite.com/manualsd.

\section{PROCEDIMENTOS DA ETAPA 2}

Os procedimentos desta etapa, conforme Figura 2, buscaram verificar a utilidade da ferramenta de simulação para a assimilação dos conceitos de gestão de sistemas de produção, principalmente para avaliar o impacto da implantação das ferramentas de produção enxuta. 
Figura 2: Fluxograma dos procedimentos da etapa 2 de pesquisa

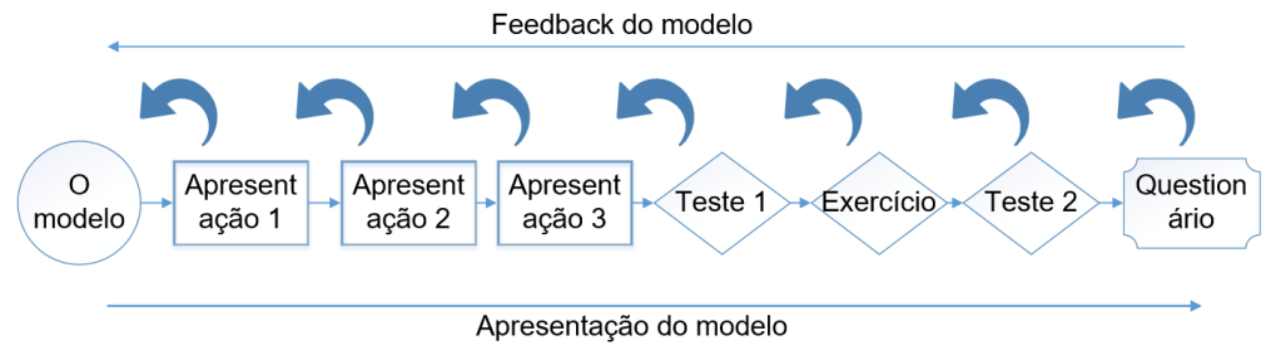

Fonte: autoria própria (2017).

A Apresentação 1 consistiu de um teste do modelo a uma aluna de finalista do curso de engenharia de produção, ou seja, com conhecimento acerca dos conceitos abordados. Desta forma, foi possível ajustar a ferramenta com base nas considerações de uma pessoa leiga no método de dinâmica de sistemas, mas com conhecimento sobre a gestão dos sistemas de produção. A Apresentação 2 envolveu um grupo heterogêneo de 6 (seis) alunos de graduação em engenharia de produção e mestrado (mas com formação em engenharia de produção). Desta forma, obteve-se um retorno de mais pessoas que possuem conhecimento sobre gestão da produção.

Após todos os ajustes, a Apresentação 3 envolveu uma atividade para 32 alunos matriculados na disciplina Gestão de Sistemas de Produção, no curso de engenharia da produção do CEUNES/UFES. Esta disciplina é oferecida no terceiro semestre do curso. O conteúdo de gestão de produção e as ferramentas da produção enxuta já haviam sido apresentados a estes alunos por meio das aulas expositivas na disciplina. Nesta etapa, foi aplicado o Teste 1 que consistia de 3 perguntas antes do contato com a ferramenta educacional desenvolvida. Estas questões buscavam avaliar o nível de conhecimento inicial dos alunos sobre conceitos de gestão de sistemas de produção abordados na disciplina. A Questão 1 indaga as vantagens de utilizar as ferramentas do Sistema Toyota de Produção (STP) quando há variações da demanda. A Questão 2 demanda o esforço que as empresas despendem para atender as variações de demanda a partir da alteração da sua capacidade produtiva. A Questão 3 solicita relacionar as ferramentas Manutenção produtiva total (TPM), Troca Rápida de Ferramentas (TRF), abastecimento dos postos de trabalho com base no JIT com os custos de produção. De posse das respostas ao Teste 1, o modelo proposto foi apresentado. Os alunos fizeram um exercício em laboratório de informática cujo objetivo era avaliar o impacto da alteração no custo de alocação de capacidade considerando o nível de implantação das ferramentas enxutas propostas no modelo.

Na etapa Exercício, foi fornecido o 'Manual para um Modelo Dinâmico Utilizando Vensim', desenvolvido para auxiliar o aluno na compreensão do modelo proposto, sua utilização no software escolhido para simulação e apresentação do exercício. $\mathrm{O}$ aluno deveria fazer uma leitura deste documento e realizar um exercício com a simulação de um cenário em que foi avaliado o impacto da alteração do percentual da capacidade requerida nos custos de produção em função dos diferentes níveis de implantação das ferramentas de produção enxuta. Esta etapa era não presencial, ou seja, os alunos não tiveram auxílio de um professor ou instrutor. Esta atividade foi desenvolvida em um prazo de uma semana. 
A etapa seguinte consistiu do Teste 2. No laboratório de informática, os alunos deveriam realizar a última simulação proposta que envolvia avaliar o impacto de diferentes estratégias de mix de produção, considerando uma penalidade para o atraso e para o mix de produção. Estas diferentes estratégias foram avaliadas em função do nível de implantação das ferramentas da produção enxuta. Feito isso, foi discutido com os alunos a interpretação de todos os resultados. Todas as dúvidas acerca da utilização do software foram sanadas. Para finalizar esta etapa, o Teste 2 consistiu de aplicar as perguntas do Teste 1 após o contato com a ferramenta educacional desenvolvida. Neste teste, além das três questões aplicadas no Teste 1 , foram feitas mais duas perguntas baseadas na simulação no modelo, acerca das vantagens em implementar as ferramentas da produção enxuta e a relação entre capacidade requerida do sistema, estoque de matéria-prima em processo e a demanda.

A Questão 4 consistiu em identificar quando é vantajoso implementar as ferramentas da produção enxuta avaliadas durante a simulação. A Questão 5 consistiu em relacionar as variáveis capacidade requerida, estoque em processo e demanda. Desta forma, este Teste 2 permitiu, após a comparação com o Teste 1 , mensurar o conhecimento adquirido a partir da utilização da ferramenta educacional, ou seja, se houve evolução no aprendizado após a ferramenta. As duas perguntas adicionadas ao Teste 2 tiveram como objetivo analisar o aprendizado do modelo proposto, ou seja, se os alunos conseguiram absorver o conhecimento proposto pelas simulações.

Por fim, a etapa Questionário, consistiu de enviar aos 32 alunos que participaram das apresentações e dos Testes 1 e 2, um questionário de avaliação da ferramenta. Esta etapa teve o objetivo de identificar as opiniões de uma maneira abrangente em relação ao modelo apresentado e o software utilizado para simulação.

\section{RESULTADOS}

O resultado deste artigo pode ser divido em duas partes, em que a primeira parte consiste em apresentar os resultados das simulações realizadas de acordo com as propostas estabelecidas. Enquanto a segunda parte consiste em descrever os resultados obtidos a partir da apresentação do modelo aos alunos de engenharia de produção, em que as notas dos Testes 1 e 2 foram utilizadas para avaliar o impacto da utilização do modelo como ferramenta educacional no conhecimento adquirido.

\section{PROCEDIMENTOS DA ETAPA 2}

Os resultados das propostas apresentaram coerência com os conceitos abordados na literatura. As Figuras 3, 4 e 5 demonstram os resultados da primeira proposta, que leva em consideração a variação da capacidade escalar. Em relação à Figura 3, para um custo elevado de alocar capacidade (10\$), o ponto de intersecção entre as três políticas se encontra aproximadamente no período de $48 \mathrm{~h}$, ou seja, antes deste período a política average lean e no lean apresentam um custo inferior ao best lean. Isso acontece porque há um custo inicial de implementação das ferramentas enxutas maior para a best lean quando 
comparado com a average lean. Porém, após o período de 48h há uma inversão dos custos totais do sistema, visto que as políticas average lean e no lean continuam crescendo linearmente, enquanto a best lean mantém um custo de produção constante ao longo do tempo. Desta forma, o custo de produção na política best lean é bem menor que nos demais casos e, com o tempo, equilibra o custo de implantação das ferramentas vinculadas à produção enxuta. Verifica-se que a política best lean apresenta melhor resultado por apresentar um menor custo total do sistema após um período de $48 \mathrm{~h}$ para um custo de alocar capacidade elevado (10\$).

Figura 3: Custo total do sistema para um custo de alocar capacidade igual a $10 \$$

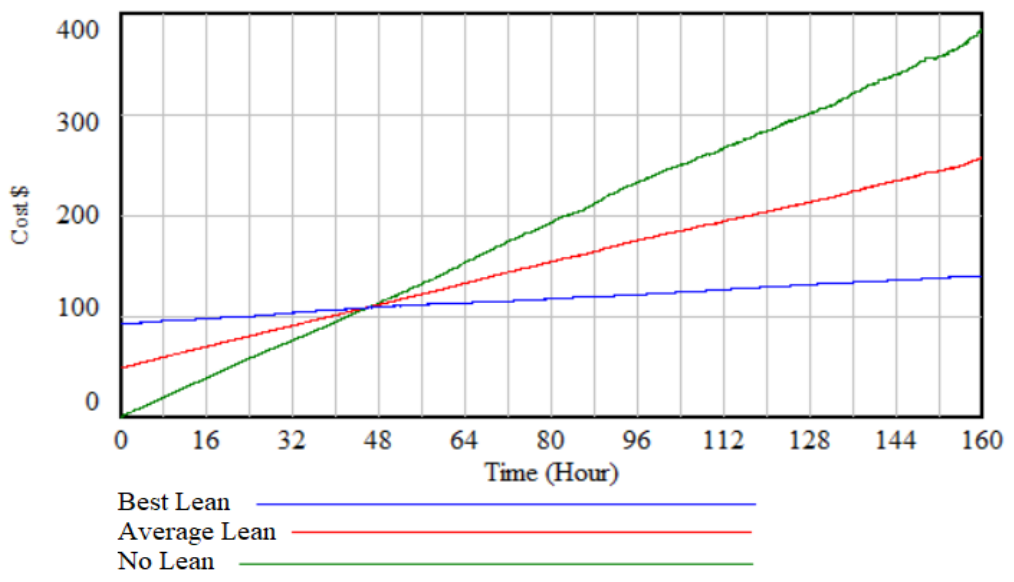

Fonte: Autoria própria (2017).

Para a Figura 4, em que o custo de alocar capacidade é igual a $5 \$$, o ponto de intersecção das três políticas ocorre no intervalo de $64 \mathrm{~h}$ e $80 \mathrm{~h}$. Neste caso, os custos do average lean e no lean são inferiores antes do período de $64 \mathrm{~h}$ e $80 \mathrm{~h}$. Porém, após este período, ocorre a inversão dos custos e a política best lean apresenta melhores benefícios no custo total do sistema. Verificou-se que, quando o custo de alocar capacidade diminui, o ponto de intersecção entre as políticas abordadas se desloca para a direita, ou seja, o período para a inversão de custos (retorno do investimento na implantação das ferramentas de produção enxuta) se torna maior.

Figura 4: Custo total do sistema para um custo de alocar capacidade igual a $5 \$$

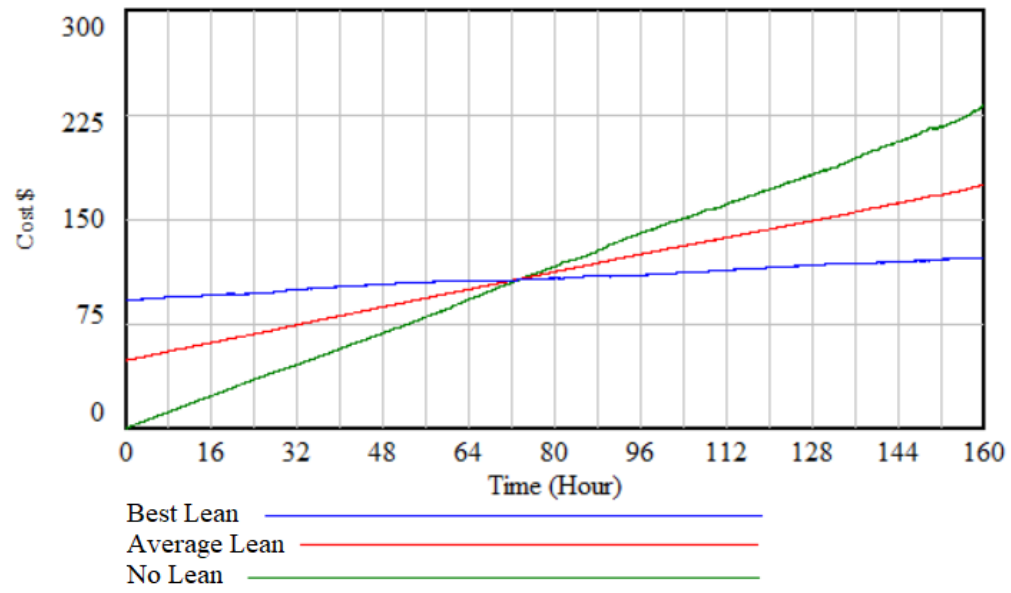

Fonte: Autoria própria (2017). 
Em relação à Figura 5, para um custo de alocar capacidade igual à \$1, o ponto de intersecção entre as três políticas ocorre no período entre $128 \mathrm{~h}$ e $144 \mathrm{~h}$, ou seja, a partir deste ponto acontece a inversão dos custos, semelhante aos cenários anteriores. Conclui-se então que, quanto menor o custo de alocar capacidade, maior será o período de inversão dos custos. Se o custo de alocar capacidade é relativamente baixo, pode não ocorrer viabilizar a implantação da produção enxuta. Neste caso, a política no lean apresentará melhores benefícios em todo o período. Porém, este caso não acontece nos cenários reais de engenharia, pois o custo de alocar capacidade é relativamente alto, sendo assim o investimento em ferramentas de produção enxuta podem minimizar os custos totais de produção. Além disso, quanto maior a eficiência destas ferramentas, mais rapidamente ocorrerá o retorno deste investimento.

Figura 5: Custo total do sistema para um custo de alocar capacidade igual a $1 \$$

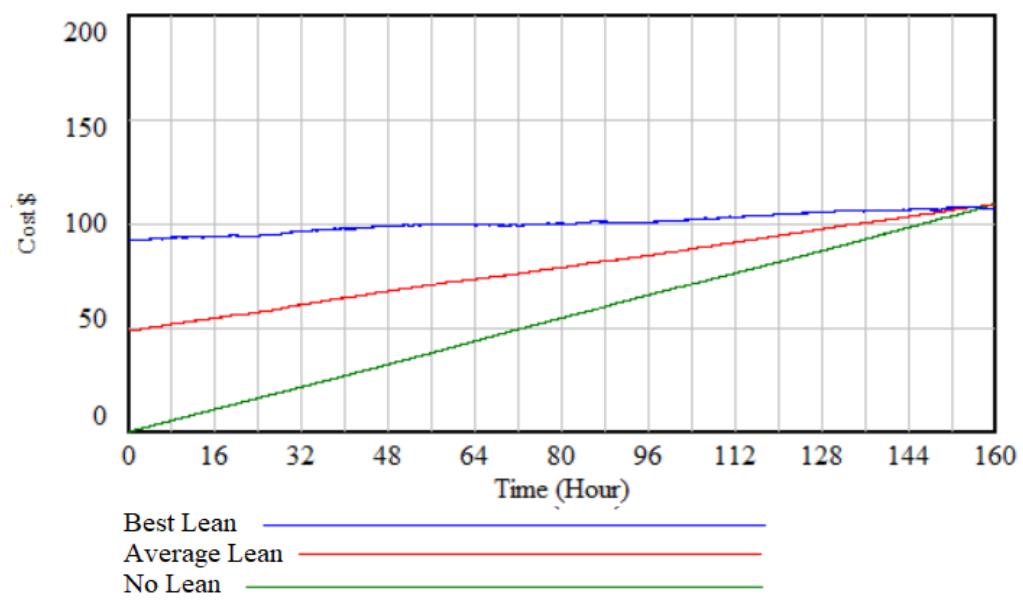

Fonte: Autoria própria (2017).

As Figuras 6, 7 e 8 se referem à segunda proposta que restringe o limite de capacidade. A Figura 6 demonstra o resultado do custo total do sistema quando a capacidade é restrita à $50 \%$, ou seja, a máxima capacidade requerida para produção é de $50 \%$. Neste caso, o ponto de intersecção entre as políticas ocorre no período de $64 \mathrm{~h}$ e $80 \mathrm{~h}$. A política no lean começa com custo zero e apresenta o maior crescimento linear dentre as políticas. A política average lean inicia com a metade dos custos da best lean e apresenta um crescimento linear menor se comparado ao custo no cenário no lean. Por fim, com a política best lean, os custos totais apresentam um comportamento constante ao longo do tempo. Com os parâmetros adotados, conclui-se que a política best lean apresenta o melhor desempenho ao longo do tempo para uma restrição de capacidade de $50 \%$. 
Figura 6: Custo total a partir de uma restrição da capacidade no valor de $50 \%$

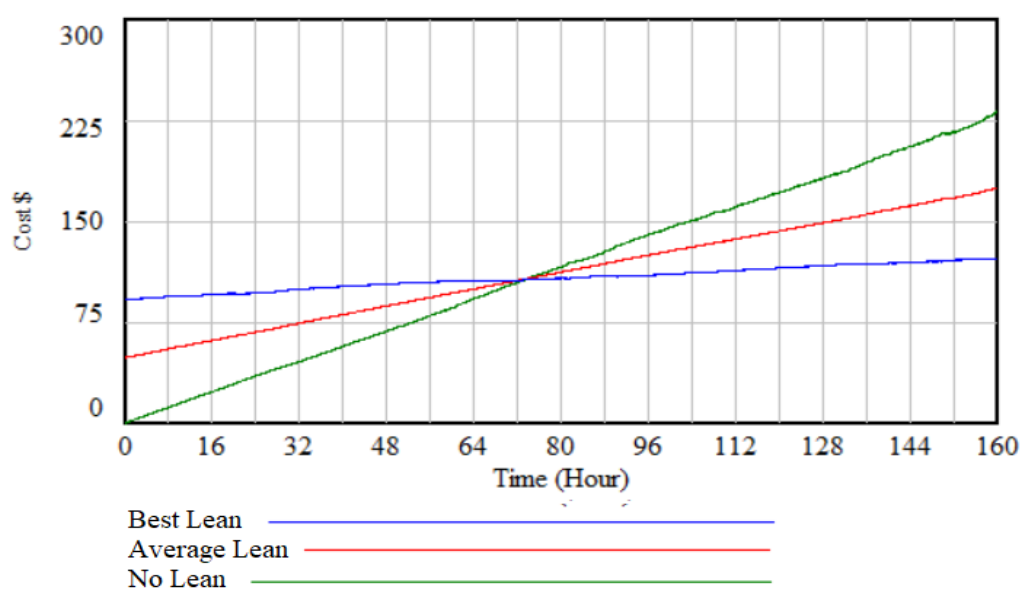

Fonte: Autoria própria (2017).

Para uma capacidade requerida com limite de 25\%, conforme a Figura 7, o comportamento da política no lean começa a se alterar. Ao restringir a capacidade para $25 \%$, os custos da política no lean foram alterados a partir do período de $128 \mathrm{~h}$, enquanto as demais políticas não apresentaram modificações significativas, ou seja, ao alterar a capacidade do sistema a política no lean apresenta variações no custo total do sistema.

Figura 7: Custo total a partir de uma restrição da capacidade no valor de $25 \%$

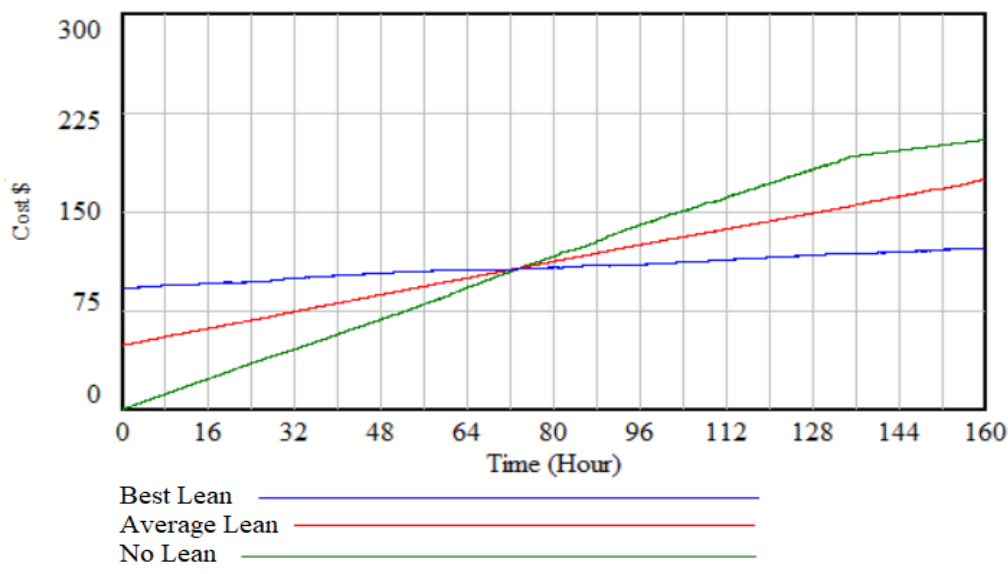

Fonte: Autoria própria (2017).

Ao diminuir a porcentagem da capacidade requerida para $12,5 \%$, conforme a Figura 8 , os custos de produção com a política best lean permanecem constantes, enquanto para a política average lean ocorre uma queda nos custos a partir do período $136 \mathrm{~h}$, e para a política no lean os custos apresentados são relativamente baixos comparado aos demais cenários. Conclui-se então, que as políticas best lean e average lean não apresentam diferenças significativas nos custos totais ao restringir a capacidade requerida, o que difere da política no lean que ao modificar a capacidade requerida seus custos totais alteram de maneira significativa. Esse comportamento pode ser decisivo para os gestores da empresa, pois ele constitui um trade-off entre custo e rápido nivelamento de produto. Para uma política no lean, ao modificar a capacidade requerida para atender uma demanda inesperada os custos serão maiores, quando comparado às políticas enxutas. 
Figura 8: Custo total a partir de uma restrição da capacidade no valor de 12,5\%

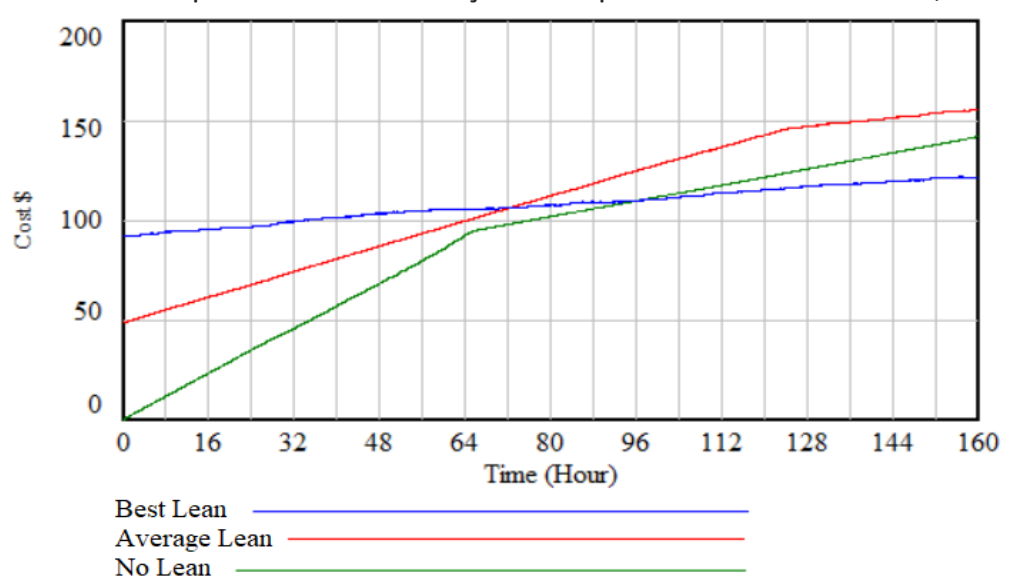

Fonte: Autoria própria (2017).

A Figura 9 apresenta a análise da terceira proposta, que leva em consideração a modificação do mix de produção. A política best lean 1 significa lotes menores, 4 setup por mês e 1 semana de atraso, a política best lean 2 significa lotes maiores, 2 setup por mês e 2 semanas de atraso. Sendo assim, até o período de $40 \mathrm{~h}$ a política best lean 2 apresenta menores custos, ou seja, lotes maiores para curto prazo possuem maiores benefícios. Porém, a partir do período de $40 \mathrm{~h}$ ocorre a inversão de custos e a política best lean 1 , ou seja, lotes menores e com maior número de setup apresenta menores custos ao longo do tempo. Conclui-se então que em longo prazo é melhor utilizar lotes menores e maiores quantidade de setup para nivelar o mix de produto, caso as ferramentas da produção enxuta estejam implantadas de forma satisfatória.

Figura 9: Custo total do sistema para diferentes políticas de mix de produto

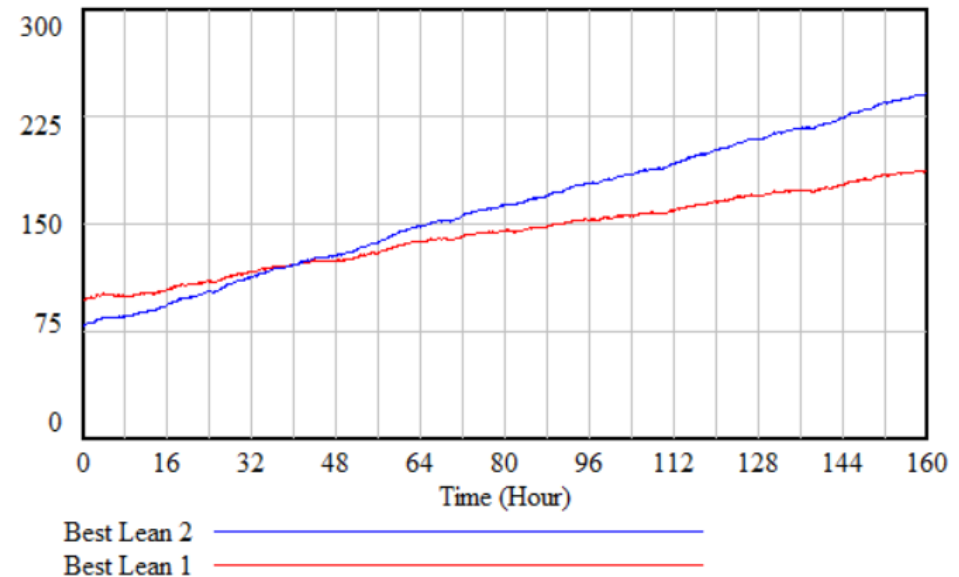

Fonte: Autoria própria (2017).

\section{AVALIAÇÃO DA FERRAMENTA EDUCACIONAL PROPOSTA}

O resultado do Teste 1, que avaliava o conhecimento dos estudantes antes da utilização desta ferramenta educacional, é apresentado na Figura 10. Para avaliar o nível de conhecimento adquirido dos alunos, as notas foram divididas em três categorias considerando como baixos os resultados de 0 à 3 , médios os resultados de 4 à 6 e altos os resultados de 7 à 10. Em relação aos benefícios que 
as ferramentas do Sistema Toyota de Produção (STP) proporcionam para atender uma demanda variada que foi avaliado na Questão 1, os alunos obtiveram uma nota média de 4,20. Para a Questão 2, que abordou uma descrição do esforço das empresas em alterar sua capacidade a partir de uma variação da demanda, a média do conhecimento dos alunos foi quantificado em 1,03. Já a relação entre as ferramentas TPM, TRF e JIT e os custos de produção abordados na Questão 3, os alunos apresentaram uma nota média de 2,37.

Figura 10: Resultado do Teste 1 em categorias de notas

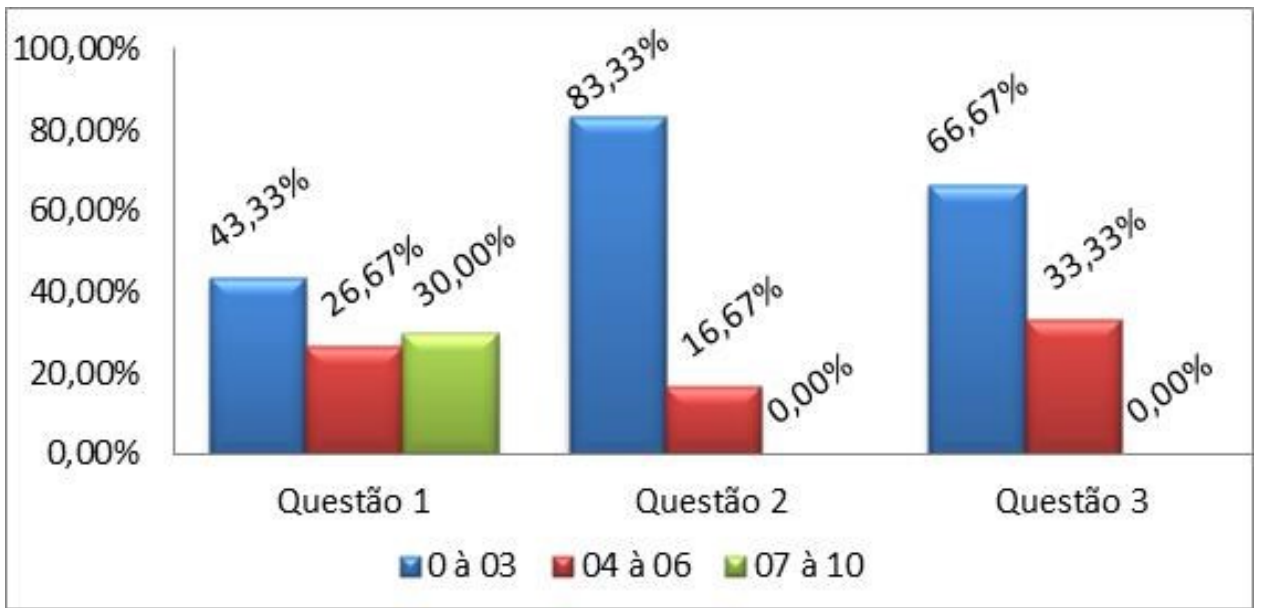

Fonte: Autoria própria (2017).

O resultado do Teste 1 mostra que dentre os assuntos abordados, os alunos demonstraram maior domínio sobre as ferramentas do STP e sua relação com a demanda variada. Percebeu-se uma maior dificuldade em descrever o esforço das empresas em alterar sua capacidade a partir de uma variação da demanda, em que $83,33 \%$ dos estudantes tem nota inferior a 4 e nenhum aluno obteve nota superior a 7 . Outra grande dificuldade é relacionar as ferramentas TPM, TRF e JIT e os custos de produção.

A Figura 11 demonstra o resultado obtido a partir do Teste 2 após a realização da simulação. Verifica-se que os alunos apresentaram notas acima de 7 para as questões 2 e 3 . Com isso, as médias dos alunos nas questões analisadas foram elevadas. A média da Questão 1 passou de 4,20 para 5,77, ou seja, um avanço de 37,4\%. Já a média da Questão 2 aumentou de 1,03 para 3,13, o que significa uma significativa evolução de $300 \%$. A Questão 3 passou de uma média de 2,37 para 4,90 , o que representa $200 \%$ de diferença.

As simulações auxiliaram os alunos a compreender melhor o esforço em alterar a capacidade para atender uma variação de demanda, assim como auxiliou a compreensão da relação entre as ferramentas TPM, TRF e JIT com o custo de produção. Dentre as três questões, a Questão 1 foi a que apresentou as melhores notas em ambos os Testes, ou seja, a partir das simulações realizadas, o conhecimento adquirido durante a disciplina de gestão e sistema de produção foram consolidados e aprimorados até para os assuntos mais dominantes. 
Figura 11: Resultado do Teste 2 em categorias de notas

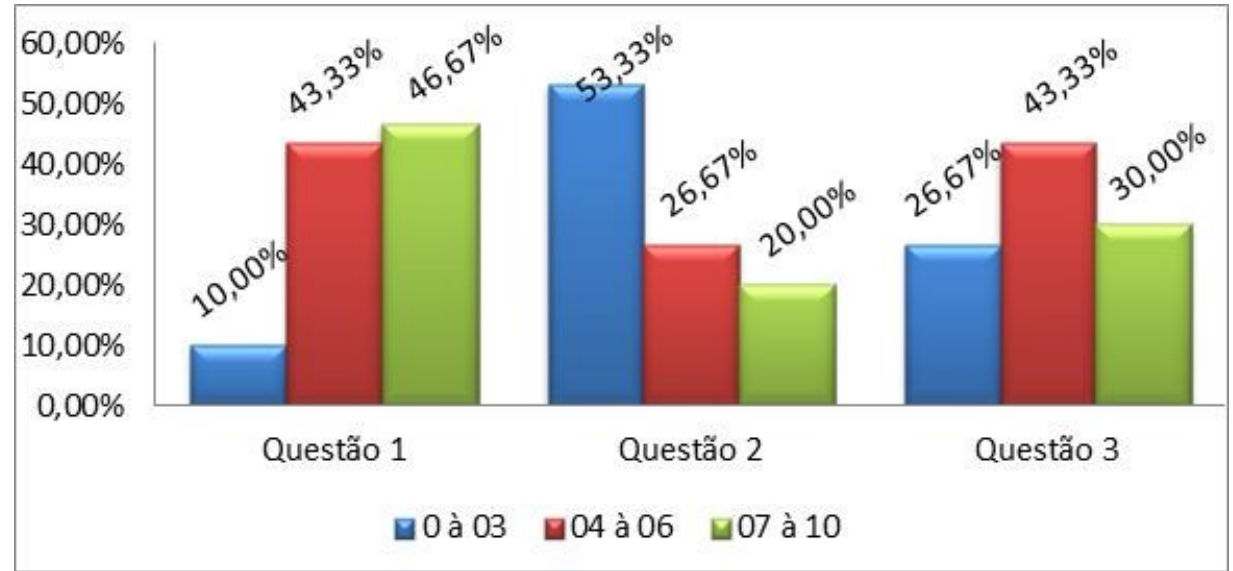

Fonte: Autoria própria (2017).

Para entender melhor a evolução no conhecimento do Teste 1 para o Teste 2, foi calculada a média e o desvio padrão das questões 1, 2 e 3 para cada aluno. Desta forma, foi possível avaliar individualmente o desenvolvimento dos estudantes.

A Figura 12 mostra a média individual da Questão 1 dos 30 alunos que participaram das simulações e seu respectivo desvio padrão. Percebe-se que apenas três estudantes apresentaram desvio padrão zero, ou seja, suas médias não foram alteradas do Teste 1 para o Teste 2. Dois destes alunos apresentaram média acima de sete, ou seja, a nota no Teste 1 já pode ser considerada elevada para a turma. Porém, destaca-se que os maiores desvios padrão são daqueles alunos que obtiveram médias relativamente baixas. Em alguns casos, o desvio padrão foi maior que a média da nota. Como houve evolução para $90 \%$ dos alunos analisados na Questão 1, percebe-se que as simulações consolidaram os conceitos de produção enxuta para alunos com melhores notas, mas principalmente para aqueles alunos cujo desempenho inicial era baixo.

Figura 12: Média e desvio padrão individual dos alunos referente à Questão 1

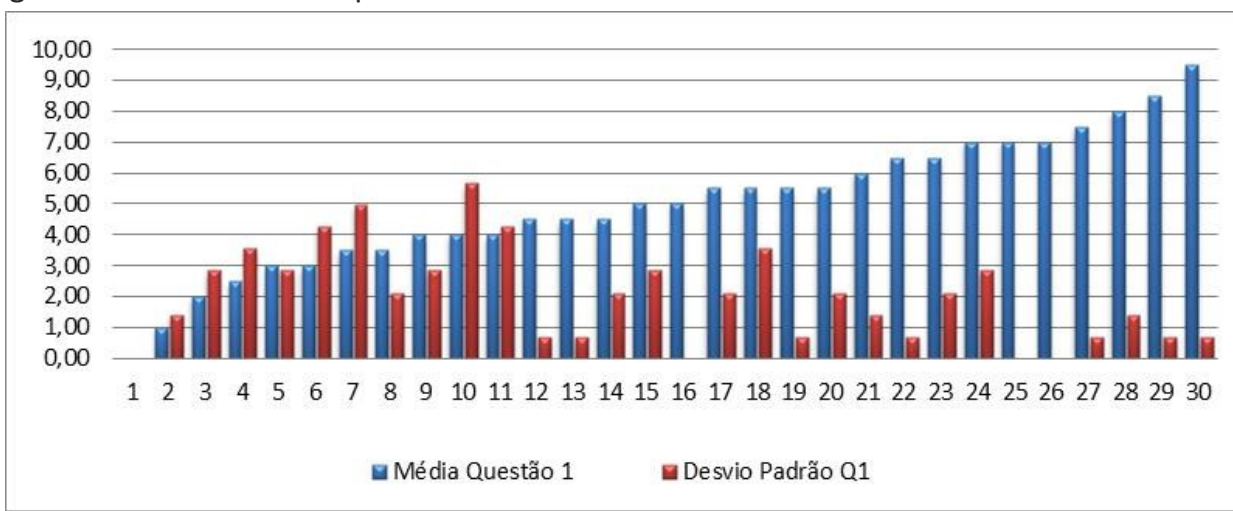

Fonte: Autoria própria (2017).

A Questão 2 apresentou a maior discrepância de notas nos Testes 1 e 2, conforme a Figura 13. Nota-se que cinco pessoas tiveram suas médias maiores que seu desvio padrão, enquanto a maioria apresentou desvio padrão superior à suas médias, ou seja, as variações de notas entre o Teste 1 e Teste 2 foram altas. As variações podem apresentar comportamento positivo ou negativo em relação 
às notas, porém a média das notas do Teste 2 foram superiores ao Teste 1 . Entretanto, nove alunos não conseguiram descrever o que as empresas deveriam fazer para alterar sua capacidade a partir de uma variação da demanda, mesmo após a simulação. Portanto, para a Questão 2, as simulações realizadas ajudaram alguns alunos a compreender melhor os conceitos sobre esforço organizacional em atender variações de demanda, mas ainda não foi suficiente para auxiliar $30 \%$ dos estudantes analisados.

Figura 13: Média e desvio padrão individual dos alunos referente à Questão 2.

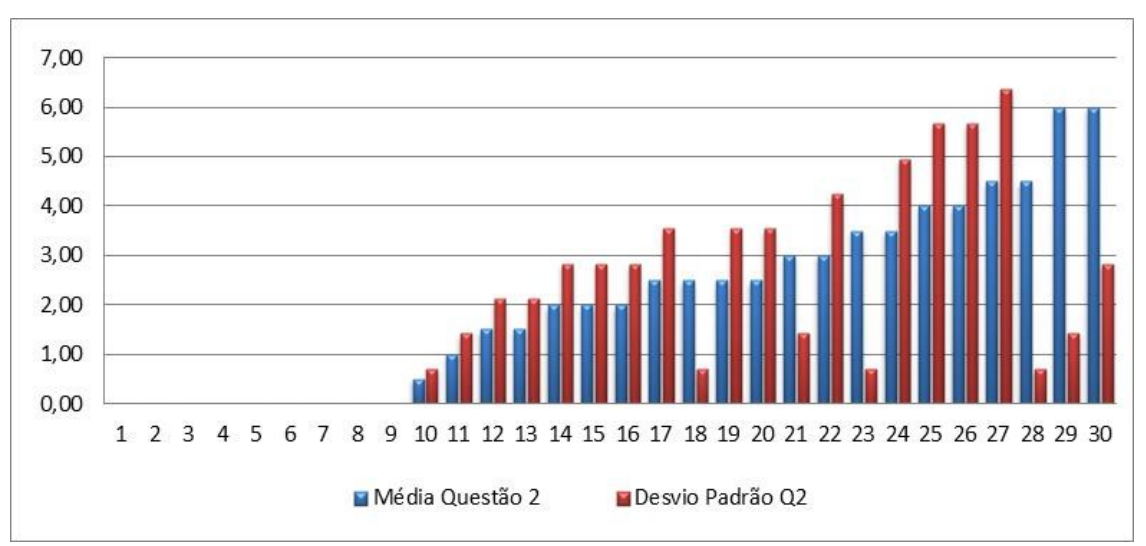

Fonte: Autoria própria (2017).

Por fim, a Figura 14 demonstra a relação das médias da Questão 3 para cada aluno e seus respectivos desvio padrão. Apenas três alunos apresentaram desvio padrão nulo, ou seja, suas notas foram as mesmas para ambos os Testes e as simulações realizadas não tiveram impacto significativo no conhecimento adquirido. A variação com a simulação para a Questão 3 pode ser considerado uma alteração positiva, pois, a média da turma foi elevada do Teste 1 para o Teste 2. Desta forma, o modelo apresentado auxiliou os alunos no entendimento das ferramentas da produção enxuta, principalmente para os alunos que não tinham o domínio do assunto.

Figura 14: Média e desvio padrão individual dos alunos referente à Questão 3.

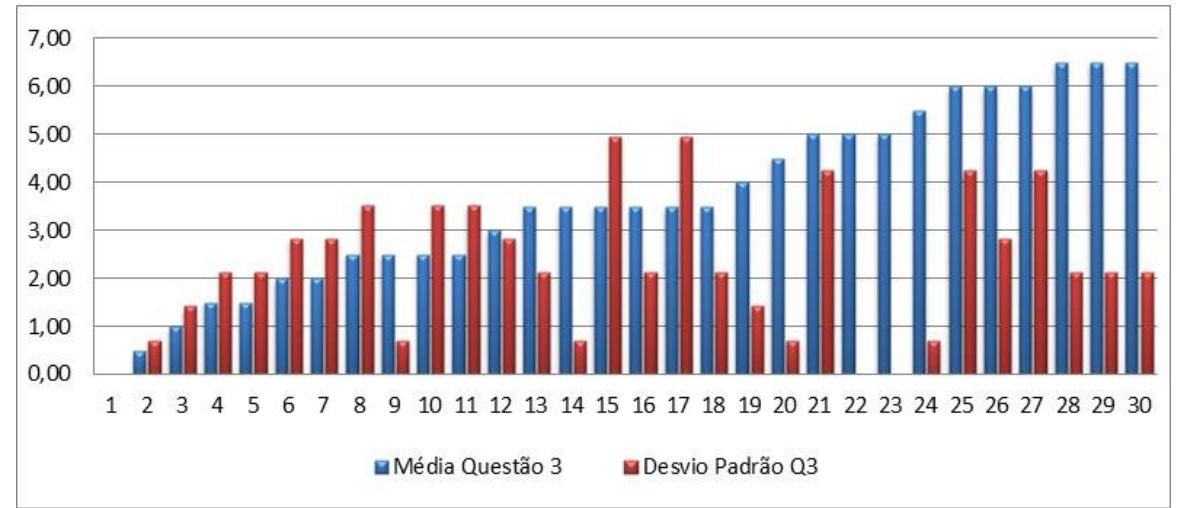

Fonte: Autoria própria (2017).

A Questão 2 obteve valores de desvio padrão mais elevados. Entretanto, nesta mesma questão, menos alunos evoluíram do Teste 1 para o Teste 2 . Portanto, a Questão 3 se destacou com a melhor evolução, pois, seu desvio padrão obteve consistência na contribuição para o aumento da média das notas. 
Embora alguns alunos tiveram notas inferiores no Teste 2 quando comparado ao Teste 1, suas médias em geral foram elevadas. Ou seja, em alguns casos o aluno não apresentou melhoria em todas as questões do Teste aplicado, houve uma redução das notas em pelo menos uma Questão.

\section{ANÁLISE DO QUESTIONÁRIO}

A partir dos resultados obtidos do questionário aplicado que se encontra disponível no sítio eletrônico https://igortz-10.wixsite.com/manualsd, foi possível obter o retorno dos alunos em relação à utilização do software e a apresentação do modelo como ferramenta educacional. A utilização do software Vensim PLE ${ }^{\circledR}$ como uma ferramenta para simulação foi bem aceita, visto que $62,5 \%$ dos estudantes a descreveram como boa, 34,4\% como muito boa e apenas 1 aluno $(3,1 \%)$ relatou como uma ferramenta razoável. Além disso, a maioria dos estudantes $(87,5 \%)$ avaliou que o software utilizado pode ser empregado para simular outros modelos da área da engenharia de produção. Os outros $6,25 \%$ não saberiam responder e 6,25\% descreveram que a utilização depende da área de atuação.

A utilização do software Vensim $\mathrm{PLE}^{\circledR}$ para simulação foi considerada complexa para $18,8 \%$ dos estudantes, razoável para $53,1 \%$, fácil para $25 \%$ ou muito fácil $(3,1 \%)$. Algumas dúvidas a respeito da utilização do Vensim $\mathrm{PLE}^{\circledR}$ foram destacadas, tais como: entender como funciona o modelo e a relação de todas as variáveis, como utilizar as ferramentas e funções do programa e implementar as equações ao modelo. Considerando que foi o primeiro contato com o aplicativo e com o modelo de simulação, a maior dificuldade de alguns estudantes pode ser avaliada como normal.

Considerando que os estudantes não tinham contato com o método de dinâmica de sistemas e ainda não haviam estudado a teoria geral dos sistemas, buscou-se verificar se os estudantes tiveram dificuldades de entender o modelo proposto. Apenas $18,7 \%$ dos estudantes julgaram o modelo confuso. Outros estudantes $(25 \%)$ afirmaram que o modelo parecia confuso, mas a leitura do manual esclareceu e complementou o entendimento. Para $46,9 \%$ dos estudantes, o modelo não era confuso, mas outros $9,4 \%$ não souberam avaliar. Dentre os $9,3 \%$ de alunos que não souberam avaliar o modelo, um aluno $(3,1 \%)$ não participou da primeira apresentação do modelo, outro aluno $(3,1 \%)$ teve suas notas abaixo da média da turma. Isso indica que $6,2 \%$ dos estudantes não haviam compreendido o modelo e, por isso, não souberam avaliar o modelo. Apenas um aluno $(3,1 \%)$ não que não soube avaliar o modelo apresentou suas médias acima da turma.

Quanto à abordagem do modelo, 75\% dos estudantes afirmaram que o modelo abordou os conceitos da produção enxuta de forma didática, enquanto $12,5 \%$ não souberam analisar. Apenas uma pessoa $(3,1 \%)$ não achou o modelo didático, que foi o aluno que não soube avaliar o modelo e apresentou notas acima da média da turma no Teste 2 , enquanto três $(9,4 \%)$ descreveram que não foi fácil interpretar os resultados e identificar algumas mudanças no modelo.

Pode-se considerar que o modelo proposto colaborou para adquirir conhecimento na área de gestão e sistema de produção, visto que $56,3 \%$ dos estudantes mencionaram que auxiliou muito, $40,6 \%$ auxiliou um pouco e apenas 
um aluno $(3,1 \%)$ mencionou que não auxiliou. Este aluno obteve notas nos Teste 1 e 2 inferiores às médias da turma, o que indica que ele apresentou dificuldades no entendimento do modelo. Portanto, para este aluno o modelo não auxiliou no conhecimento adquirido.

O modelo proposto auxiliou a maioria dos alunos a verificar o impacto da implementação de algumas ferramentas da produção enxuta (TPM, TRF, JIT) nos custos de produção. Cerca de $50 \%$ dos estudantes afirmaram que o modelo auxiliou muito na compreensão da relação entre as ferramentas propostas e o custo do sistema de produção, enquanto $46,9 \%$ julgaram que auxiliou um pouco. Apenas um aluno $(3,1 \%)$ não soube avaliar os benefícios da ferramenta, este aluno foi o mesmo mencionado anteriormente, que apresentou notas inferiores à média da turma e descreveu o modelo como confuso e sem didática.

A partir da simulação realizada, o modelo proposto proporcionou maior compreensão do comportamento das variáveis estudadas ao longo do tempo: para $56,3 \%$ dos estudantes auxiliou muito, para $37,5 \%$ auxiliou um pouco. Apenas $6,2 \%$ dos alunos não souberam avaliar. Dentre estes, um aluno $(3,1 \%)$ não soube avaliar os benefícios da ferramenta apresentada, que foi o mesmo mencionado anteriormente, ou seja, dentre os 32 alunos que foram aplicados o questionário, somente um relatou que o modelo foi confuso, sem didática, que o modelo não auxiliou a verificar o impacto das ferramentas da produção enxuta e que as simulações não auxiliaram a esclarecer o comportamento das variáveis estudadas.

Em relação à dificuldade em interpretar os resultados gerados da simulação, as respostas apresentaram algumas divergências: $12,5 \%$ dos alunos tiveram muita dificuldade em interpretar os resultados, $37,5 \%$ mencionaram pouca dificuldade, para uma pessoa foi indiferente, $25 \%$ descreveram como pouca facilidade e $21 \%$ muita facilidade. Os resultados gerados a partir da simulação não foram triviais para a maioria dos alunos. Como o método de dinâmica de sistemas envolve uma relação complexa das variáveis no tempo, seu entendimento requer um determinado nível de conhecimento e uma maior experiência.

Cada aluno destacou as dúvidas com a utilização a simulação, cuja frequência de indicação está na Tabela 1.

Tabela 1: Dúvidas na simulação.

\begin{tabular}{cc} 
Dúvidas & Quantidade \\
Utilização do software & 16 \\
Modelo & 12 \\
Interpretação dos resultados & 6 \\
Entender os cenários & 2 \\
Entender o manual & 1 \\
Total & $\mathbf{3 7}$ \\
\hline
\end{tabular}

Fonte: Autoria própria (2017).

O total de dúvidas excedeu o número de alunos que participaram da simulação, pois, alguns alunos apresentaram mais de uma dúvida enquanto três alunos afirmaram que não tiveram dúvidas na simulação. A principal dificuldade foi na utilização do software Vensim PLE ${ }^{\circledR}$. Como já mencionado, este foi o primeiro contato dos estudantes com o aplicativo e essa dificuldade em 
experimentar algo novo é esperada. A manipulação do software não foi algo fácil e intuitivo, apresentando assim dúvidas em relação ao manuseio das ferramentas. Além disso, este também foi o primeiro contato dos estudantes com o método de dinâmica de sistemas, o que também pode influenciar para que o modelo seja o item citado em segundo lugar quanto às dúvidas. Os resultados gerados a partir das propostas não foram triviais. A análise dos resultados requeria conhecimento sobre gestão e sistemas de produção, um conteúdo que estava sendo aprendido pelos alunos.

Por fim, a ferramenta educacional proposta foi comparada com os livros didáticos utilizados na disciplina. Desta forma, a maioria dos estudantes $(81,25 \%)$ descreveu o modelo como uma ferramenta complementar aos livros enquanto uma minoria $(12,5 \%)$ indicou o modelo melhor que os livros didáticos para a aquisição de conhecimento acerca do tema. Apenas 6,25\% dos estudantes não souberam analisar. Portanto, apesar das dificuldades ou dúvidas na utilização do software ou de compreensão do modelo, os estudantes foram receptivos à ferramenta educacional.

\section{CONSIDERAÇÕES FINAIS}

A dinâmica de sistemas é uma metodologia que pode ser aplicada para diversos fins, tal como para modelos de simulação computacional como o que foi abordado neste trabalho. Este artigo utilizou um modelo de gestão e sistemas de produção que abordou os conceitos de demanda, produção enxuta, atraso de pedidos e estoque buscando minimizar o custo de produção. Os resultados obtidos a partir das simulações do modelo realizadas foram coerentes com os conceitos encontrados na literatura. A implementação das ferramentas da produção enxuta apresentaram maiores benefícios quando analisados em longo prazo.

Buscou-se, com este modelo, propor uma ferramenta educacional que auxiliasse alunos de ensino superior na consolidação de conceitos de gestão de sistemas de produção, mas que verificassem a relação complexa de variáveis deste sistema no tempo. A simulação deste modelo pelos alunos de Engenharia de Produção permitiu averiguar seu emprego enquanto ferramenta educacional.

Os estudantes conseguiram ampliar seu conhecimento a partir da simulação realizada. Em todas as questões que aferiram a evolução do conhecimento adquirido houveram melhorias significativas, apesar de diferentes dimensões. Os resultados demonstraram que as melhorias foram mais significativas para os alunos que tiveram suas notas em torno da média ou baixas. Portanto, o modelo apresentado é uma ferramenta didática e que teve um impacto maior aos alunos que não apresentaram domínio total sobre o assunto, contribuindo para o aprendizado.

As dúvidas mais frequentes do modelo apresentado foi à utilização das ferramentas do software Vensim PLE ${ }^{\circledR}$. O principal motivo para que esta dúvida fosse a mais frequente é que nenhum aluno estava familiarizado com o programa, sendo assim houve dificuldade em identificar as funcionalidades do programa e utilizá-las para realizar as simulações propostas. A dificuldade na compreensão do modelo pode ser explicada pela imaturidade na compreensão do método de dinâmica de sistemas. Os alunos não tinham experiências em 
abordagens que permitem representar a complexidade da relação entre as variáveis relacionadas em sistemas reais de gestão de produção. As relações representadas no modelo não são triviais ou simples de serem visualizadas em aplicações reais de engenharia, o que torna a interpretação difícil durante a prática da simulação pela primeira vez.

O modelo desenvolvido apresentou resultados satisfatório e condizente com o que foi proposto e teve uma boa aceitação pelos alunos como um material didático. O resultado demonstrou que o modelo pode ser utilizado como uma ferramenta educacional complementar para os alunos de engenharia, com o intuito de aprimorar o conhecimento em gestão de sistemas de produção. 0 modelo pode ser utilizado como jogos de simulação cujo objetivo é de auxiliar a tomada de decisão do usuário em um cenário pré-definido. Com isso, empresas de pequeno e médio porte podem utilizar o modelo como uma alternativa para auxiliar a tomada de decisão em determinados cenários. O modelo apresentado é uma ferramenta simples de manuseio e disponibilizada de maneira gratuita para simulação, sendo assim não há necessidade de investimento com softwares avançados.

Entretanto, a aplicação deste modelo no setor industrial não foi objetivo deste artigo e segue como sugestão para pesquisas futuras. Além disso, como uma parcela significativa de alunos não conseguiram descrever o que as empresas deveriam fazer para alterar sua capacidade a partir de uma variação da demanda (Questão 2 dos testes), mesmo após a simulação, outros cenários podem ser desenvolvidos em pesquisas futuras buscando melhorar este aprendizado.

A maior dificuldade encontrada para realização deste trabalho foi a construção do modelo e como adaptá-lo para um cenário específico. Este trabalho contribuiu para propiciar uma ferramenta simples e gratuita que pode ser utilizada para fins educacionais por estudantes ou para auxílio à tomada de decisão por pequenas e médias empresas. 


\title{
Management system production: an educational tool with system dynamics
}

\begin{abstract}
An understanding of how the company in the face of the market or the myriad strategic, political, organizational and marketing changes that occurs over time and strategically. Despite the importance, the managers challenge and keep themselves updated about their organization and the market. For students, one difficulty is to visualize the impact of the relationship between these factors. The system dynamics method is quite applied to situations such as what is qualitative as well as how much quantitative in a complex system. With this, a management model and production system was developed from the dynamic systems methodology in which the concepts of production, demand, delay, inventory and production are related and different strategies can have their impact evaluated. This model was evaluated and not educated in teaching the production engineering course of a federal university. It was verified that the dynamics of auxiliary systems not learned from the content of the discipline and possibility to evaluate the impacts of the change of strategy in the management of production systems. The students were receptive to the tool they want in other models of simulations. It is hoped that this model is also useful for managers in assessing the organization's positioning in their business environment.
\end{abstract}

KEYWORDS: System dynamics. Management and production system. Educational tool. Simulation games. Lean production. 


\section{REFERÊNCIAS}

AHMAD, M. F., ZAKUAN, N., JUSOH, A., \& TAKALA, J. Relationship of TQM and business performance with mediators of SPC, lean production and TPM.

Procedia-Social and Behavioral Sciences, 65, 186-191, 2012. crossref

ALVEZ, L. B. Aplicação da dinâmica de sistemas no planejamento de projetos de desenvolvimento: projetos de habitação social. 2008. 163 f. Dissertação (Mestrado em Engenharia de Produção) - Programa de Pós-Graduação em Engenharia de Produção, Universidade Federal de Santa Catarina, Florianópolis, 2008.

ANTUNES, J.; ALVAREZ, R.; BORTOLOTTO, P.; KLIPPEL, M.; PELLEGRIN, I. Sistemas de produção: conceitos e práticas para projetos e gestão da produção enxuta. Bookman Editora, 2008.

CHUNG, S.; HORAD, J.; HOVMAND, P. A Developmental Framework for Assessing Application of Systems Thinking and Systems Dynamics in Teams and Organizations. . In: 32nd International Conference of the System Dynamics Society, Delft, The Netherlands. Anais...p.1387, 2014.

DAALEN, C.V.; SCHAFFERNICHT, M.; MAYER, I. System Dynamics and Serious Games. . In: 32nd International Conference of the System Dynamics Society, Delft, The Netherlands. Anais... p.1141, 2014.

DEIF, A. M.; ELMARAGHY, H. Cost performance dynamics in lean production leveling. Published in: the Journal of Manufacturing Systems. v. 33, n. 4, p. 613, 2014.

DREWS, T. et al. Value-focused Design of Lean Production Systems Based on a System Dynamics Approach. Procedia CIRP, v. 50, p. 478-483, 2016. crossref

ELMASRY, S.S.; SHALABY, M.A.; SALEH, M.M. A System dynamics simulation model for scalable-capacity manufacturing systems. . In: 30th International Conference of the System Dynamics Society, July $22-26$, St. Gallen, Switzerland. Anais... p.1231, 2012.

FERRADÁS, P. G., \& SALONITIS, K. Improving changeover time: a tailored SMED approach for welding cells. Procedia CIRP, 7, 598-603, 2013. crossref

FORRESTER, J. W. Industrial Dynamics. Cambridge: Productivity Press, 1972. 
FORRESTER, J. W. The beginning of system dynamics. McKinsey Quarterly, p. 417, 1995.

GEORGIADIS, P.; MICHALOUDIS, C. Real-time production planning and control system for job-shop manufacturing: A system dynamics analysis. European Journal of Operational Research, v. 216, n. 1, p. 94-104, 2012. crossref

HAAG, H.; TILEBEIN, M. I. System Dynamics in a Strategic Foresight Process for Firms in Production Networks. In: 30th International Conference of the System Dynamics Society July 22 - 26, St. Gallen, Switzerland. Anais... p.1103, 2012.

LEITE, J. P.; BELTRÃO, M.J.C.; CHEBAR, I.E.; RAMIREZ, N.I.B. Avaliação preliminar do impacto de softwares de simulação no ensino das Engenharias Química e de Petróleo. Engevista, v. 16, n. 1, p. 28-40, 2014.

MAIER, F. H. Competitiveness in Manufacturing as Influenced by Technology Some Insights from the Research Project: World Class Manufacturing. In: The 15th International Conference of the System Dynamics Society, Istanbul, Turkey . Anais... 1997.

MASHAYEKHI, A. N. Oscillation in Preventitive Maintenance Programs In: The 14th International Conference of the System Dynamics Society, Cambridge, Massachusetts, USA. Anais... p. 361, 1996.

OREFICE, R.; MORAES, E. SYSTEM DYNAMICS A bibliometric analysis of System Dynamics Review. In: THE 33th INTERNATIONAL CONFERENCE OF THE SYSTEM DYNAMICS SOCIETY, Cambridge, USA. Anais... p.1378, 2015

ÖZGÜN, O.; BARLAS, Y. Effects of delay, nonlinearity and feedback on the overall complexity of a stock management game. In: THE 30th INTERNATIONAL CONFERENCE OF THE SYSTEM DYNAMICS SOCIETY, St. Gallen, Switzerland. Anais... p.1337, 2012.

PASQUALINI, F.; LOPES, A.O.; SIEDENBERG, D. Gestão da produção. Ijuí, Rio Grande do Sul, Brasil. (Editora Unijuí), 2010.

ROMAN, D. J.; PIANA, J.; LOZANO, M.A.S.P.L.; MELLO, N.R.; ERDMANN, R.H. Fatores de competitividade organizacional. BBR-Brazilian Business Review, v. 9, n. 1, 2012. 
SAVSAR, M., \& ABDULMALEK, F. Modeling of a pull-push assembly control system to minimize inventory and demand delay costs. International Journal of Industrial Engineering: Theory, Applications and Practice, 15(1), 83-91, 2008;

SEDDON J.; CAULKIN S. Systems thinkings, lean production and action learning. Action Learning: Reserch and Pratice, 2008.

STERMAN, J.D. Business Dynamics: systems thinking and modeling for a complex world. Boston: Irwin/ McGraw - Hill, 2000

STRAUSS, L.M. Um modelo em dinâmica de sistemas para o ensino superior. Dissertação (Mestrado em Administração) - Universidade Federal do Rio Grande do Sul, 2010.

THURLBY, R. K.; CHANG, J. O. The Applications of System Dynamics to ReEngineering of Value. In: The 12th International Conference of the System Dynamcs Society, Stirling, Scotland. Anais... p.59, 1994

WOMACK, J. P., \& JONES, D. T. Beyond Toyota: how to root out waste and pursue perfection. Harvard business review, 74(5), 140, 1996.

Recebido: 09 out. 2017

Aprovado: 23 mai. 2018

DOI: 10.3895/gi.v14n3.7163

Como citar:

ZANCHETTA, I. T.; CHAVES, G. L. D. Gestão de sistemas de produção: uma ferramenta educacional com o método dinâmica de sistemas. R. Gest. Industr., Ponta Grossa, v. 14, n. 3, p. 63-87, jul./set. 2018

Disponível em: $\leq$ https://periodicos.utfpr.edu.br/rgi >. Acesso em: XXX.

Correspondência:

Igor Zanchetta

Rua Lizete Conde Rios Cavalcanti, 212, Sâo Mateus, Espirito Santo, Brasil.

Direito autoral: Este artigo está licenciado sob os termos da Licença Creative Commons-Atribuição 4.0

Internacional. 